\title{
Diagnostic and prognostic potential of MIB-1 proliferation index in thyroid fine needle aspiration biopsy
}

\author{
ANASTASIOS SOFIADIS ${ }^{1,2}$, EDNEIA TANI ${ }^{3,4}$, THEODOROS FOUKAKIS ${ }^{1,4}$, PETRA KJELLMAN ${ }^{1,2}$, \\ LAMBERT SKOOG ${ }^{3,4}$, ANDERS HÖÖG ${ }^{3,4}$, GÖRAN WALLIN ${ }^{2}$, JAN ZEDENIUS ${ }^{2}$ and CATHARINA LARSSON ${ }^{1}$ \\ ${ }^{1}$ Department of Molecular Medicine and Surgery, Section of Medical Genetics; \\ ${ }^{2}$ Department of Molecular Medicine and Surgery, Section of Endocrine Surgery, Karolinska Institutet; \\ ${ }^{3}$ Department of Pathology-Cytology; ${ }^{4}$ Department of Oncology-Pathology, Karolinska Institutet, \\ Karolinska University Hospital, SE-171 76 Stockholm, Sweden
}

Received February 23, 2009; Accepted May 4, 2009

DOI: 10.3892/ijo_00000348

\begin{abstract}
Fine needle aspiration biopsy (FNAB) is the preferred technique for the initial diagnostic evaluation of thyroid lesions, which nevertheless poses a diagnostic challenge for all clinicians involved. The latter necessitates the use of molecular markers on thyroid cytology. MIB-1 is a molecular marker already used in the cytological evaluation of various tumors. In this study, we assessed whether MIB-1 proliferation index adds diagnostic information to the conventional cytological analysis of thyroid nodules and prognostic information in thyroid cancers. MIB-1 index for various thyroid lesions was retrospectively reviewed in a series of 504 patients. Furthermore, the prognostic value of MIB-1 index was investigated for 183 of the patients with papillary thyroid cancer (PTC). MIB-1 index was significantly higher in anaplastic thyroid cancer (ATC) compared to other tumor types $(\mathrm{p}<0.01)$. No significant difference in MIB-1 index was observed between thyroid adenomas and follicular carcinomas. In PTC, MIB-1 index equal to or $>4 \%$ was found to be an independent factor significantly associated with higher risk of distant metastasis and disease-related mortality $(\mathrm{p}<0.05)$. Conclusively, this study shows that preoperative MIB-1 index assessment in FNAB of thyroid nodules offers little diagnostic information as far as follicular tumors are concerned. In cases of PTC, though, MIB-1 may serve as a prognostic indicator of disease spreading and poor survival and hence influence the planning of the overall treatment scheme.
\end{abstract}

Correspondence to: Dr Anastasios Sofiadis, Karolinska University Hospital (Solna), CMM L8:01, SE-171 76, Stockholm, Sweden E-mail: anastasios.sofiadis@ki.se

Key words: thyroid, cytology, fine needle aspiration biopsy, MIB-1, Ki-67, prognosis

\section{Introduction}

Thyroid nodules are common in clinical practice and their prevalence depends on the population evaluated as well as the screening method used (1). A small proportion represents thyroid cancer, which today constitutes $\sim 1 \%$ of all malignancies worldwide (2). Traditionally, thyroid carcinomas are classified into five major groups: follicular (FTC), papillary (PTC), medullary (MTC), poorly differentiated (PDTC) and anaplastic (ATC) thyroid cancer, based on histopathology (3). The benign counterpart follicular thyroid adenoma (FTA) comprises the majority of follicular thyroid tumors.

The initial diagnostic approach of thyroid nodules is fine needle aspiration biopsy (FNAB). FNAB is a low cost, minimally invasive technique which is devoid of serious complications and has an overall high sensitivity (4). However, follicular lesions such as hyperplastic nodules (often a part of a multinodular goiter rather than a true neoplasm), FTA, FTC and variants thereof are difficult to diagnose conclusively at cytology. Additionally, the prognostic value of FNAB is limited in cases of differentiated thyroid carcinoma. The application of molecular markers on thyroid FNAB is an attractive possibility to improve the diagnostic and prognostic information (5). One such candidate is MIB-1 which in immunohistochemical analyses of post-operative specimens was suggested to be of value in establishing the prognosis of PTC (6).

$\mathrm{Ki}-67$ is a nuclear antigen expressed in proliferating cells and MIB-1 is a monoclonal antibody raised against recombinant parts of Ki-67 (7). The proportion of MIB-1positive cells, i.e. MIB-1 proliferation index, has been studied in many types of tumors and is commonly found to be of significant prognostic value (8). In thyroid specimens, several immunohistochemistry studies have suggested that MIB-1 index has no additive diagnostic value $(9,10)$. However, we recently carried out a study on 30 PTC patients by evaluating their clinical follow-up and post-operative MIB-1 index. The results indicated that MIB-1 analysis could have prognostic value in PTC (11). In the present study, we aimed at investigating the potential value of MIB-1 staining as a 
prognostic and/or diagnostic tool in preoperative FNAB from various thyroid lesions.

\section{Materials and methods}

Patients. All patients for whom MIB-1 index had been routinely determined on thyroid FNAB from 1987 until 2005 at the Division of Clinical Cytology at Karolinska University Hospital in Stockholm were retrospectively reviewed (Table I). The final diagnoses were established in the routine work-up of histopathology according to the WHO classification (3) and, in addition, uncertain cases were reviewed. These 504 cases of primary tumors included 69 cases of FTA [of which 16 were atypical (AFTA) meaning follicular neoplasms of high cellularity, nuclear atypia or unusual histologic patterns that nevertheless lack vascular and capsular invasion] (3), 25 FTC, 39 Hürthle cell adenomas (including 5 atypical), 16 Hürthle cell carcinomas, 185 PTC, 21 MTC, 9 PDTC and 24 ATC. The remaining 116 cases were non-neoplastic processes and diagnosed as goiter/ adenomatous hyperplasia or thyroiditis (including Hashimoto's disease).

For 183 of the 185 PTC patients, extensive characterization and follow-up were carried out. Patient and tumor characteristics are summarized in Table II. Two cases of tall-cell variant and 5 of follicular variant were included in this population. The patients were operated on between 1990 and 2005 at the Endocrine Surgical Unit at Karolinska University Hospital and the clinical status of living patients was updated in 2007, thereby extending their follow-up time. Clinical details for a subset of PTC cases have been reported by Kjellman et al (11).

FNAB cytology and Ki-67/MIB-1 immunocytochemistry. Aspirations were performed routinely, as previously published (12). One part of the aspirate was used for the cytological evaluation and a second part was used to determine the MIB-1 index. The air-dried smears for analysis of cell proliferation were fixed in acetone or buffered $4 \%$ formaldehyde solution and incubated with the Ki-67 (until 1993) or MIB-1 (after 1993) antibody as previously described $(13,14)$. In 1993 cytologists switched from Ki-67 antibody to MIB-1, since the latter can be used on formalin-fixed material without the need for immediate staining. The two antibodies have previously been demonstrated to give analogous results in terms of proliferation index, both in our own practice on cytology samples (13) and by others (14).

For the detection of Ki-67 (Dako, Glostrup, Denmark), immunoperoxidase ABC method was applied, whereas MIB-1 (Immunotech, Marseille, France) was detected with immunoperoxidase-avidin-biotin technique. The proliferation index was determined on a regular, clinical routine practice by scoring 200 cells in 4 microscopic fields at a magnification of $\mathrm{x} 400$. This was in agreement with the guidelines issued by both the American and the British Thyroid Associations regarding 'adequate fine needle aspiration' $(15,16)$. In the earlier parts of the study, analyses of reactive lymph nodes were included as positive control, which revealed distinct nuclear staining. Omission of the primary antibody served as negative control, whereby no staining was observed.
Statistical analyses. Kruskal-Wallis one-way ANOVA by ranks was used to compare MIB-1 index values among the diagnostic groups in the cohort of 504 patients. All p-values were further corrected according to the Bonferroni adjustment for multiple comparisons to the level of significance of 0.0008 . Mann-Whitney U test was adopted to investigate the probable correlation of MIB-1 index with a variety of clinical variables at the time of operation, such as age, gender, tumor size, tumor multifocality, presence of lymph node or distant metastasis and tumor's extrathyroidal growth. The age and size intervals applied were according to guidelines by the American Joint Committee on Cancer (AJCC) (17). The prognostic usefulness of MIB-1 index, as well as the above mentioned clinical characteristics, in the 183 PTC patients were assessed by survival analysis. At first, univariate analysis by Kaplan-Meier curves for the clinical parameters determined at follow-up was done and p-values were calculated implementing log-rank test. The end-points analyzed were local recurrence, distant metastasis and death of disease (disease-related mortality). The optimal cut-off value for MIB-1 index was determined by calculating ROC (Receiver Operating Characteristic) curves (data not shown). Finally, the statistical evaluation was completed by a multivariate analysis applying a proportional hazards regression model (Cox regression). For all survival analysis a $\mathrm{p}$-value $<0.05$ was considered significant.

\section{Results}

MIB-1 index as a diagnostic tool in thyroid nodular disease. MIB-1 proliferation index determined routinely on FNAB in 504 cases of various thyroid lesions was retrospectively evaluated. An example of MIB-1 staining in FNAB is shown in Fig. 1. Overall, positive staining ranging from $>2$ nuclei to $100 \%$ was observed in 489 of the 504 cases. The mean MIB-1 index was significantly higher in ATC (42.6\%) as compared to other tumors and benign lesions $(\mathrm{p} \leq 0.01)$, such as goiter/ adenomatous hyperplasia (1.6\%) and thyroiditis (4.2\%), with the exception of PDTC and atypical Hürthle adenoma (Fig. 2 and Table I). No significant differences were observed either between FTA and FTC, or between FTC and PTC. The mean values for MIB-1 index in these groups were $1.6 \%$ (FTA), $3.5 \%$ (FTC) and $2.9 \%$ (PTC).

Prognostic value of preoperative MIB-1 index in PTC patients. In 183 PTC patients, MIB-1 index was analyzed in relation to clinical characteristics at the time of surgery as well as in relation to clinical parameters from the follow-up. MIB-1 index did not correlate significantly with clinical variables at operation, such as lymph node or distant metastasis, multifocal tumors, extrathyroidal tumor growth, tumor size, gender or age at diagnosis.

Univariate survival analysis was initially carried out by plotting Kaplan-Meier curves. This analysis revealed that a high MIB-1 index (index value $\geq 4 \%$ ) was significantly associated with an increased risk of disease-related mortality $(\mathrm{p}=0.0001)$ and distant metastasis $(\mathrm{p}=0.00035)$ (Fig. 3). Furthermore, tumor size appeared as a significant prognostic factor of these end-events ( $\mathrm{p}=0.0056$ and 0.001 respectively) as well as of local recurrence ( $\mathrm{p}=0.00003$ ) (Fig. 4). Multivariate analysis (Cox or proportional hazards regression) was finally 
Table I. Diagnostic groups and MIB-1 index from 504 thyroid fine needle aspiration biopsies.

\begin{tabular}{|c|c|c|c|c|}
\hline \multirow[b]{2}{*}{ Diagnosis $^{\mathrm{a}}$} & \multirow[b]{2}{*}{$\mathrm{N}$} & \multicolumn{3}{|c|}{ MIB-1 index (\%) } \\
\hline & & Mean & Median & Range \\
\hline Follicular thyroid adenoma - FTA & 53 & 1.6 & 1.0 & $(0-6)$ \\
\hline Atypical follicular thyroid adenoma - AFTA & 16 & 3.0 & 2.0 & $(0.5-15)$ \\
\hline Follicular thyroid carcinoma - FTC & 25 & 3.5 & 2.5 & $(0.5-13)$ \\
\hline Hürthle cell adenoma - Hü ad & 34 & 1.9 & 1.0 & $(0-10)$ \\
\hline Atypical Hürthle cell adenoma - At Hü ad & 5 & 6.6 & 2.0 & $(1-25)$ \\
\hline Hürthle cell carcinoma - Hü ca & 16 & 3.8 & 2.75 & $(0.5-10)$ \\
\hline Papillary thyroid carcinoma - PTC & 185 & 2.9 & 2.0 & $(0-40)$ \\
\hline Medullary thyroid carcinoma - MTC & 21 & 4.4 & 2.0 & $(0.5-20)$ \\
\hline Poorly differentiated thyroid carcinoma - PDTC & 9 & 13.1 & 6.0 & $(0-50)$ \\
\hline Anaplastic thyroid carcinoma - ATC & 24 & 42.6 & 42.5 & $(10-100)$ \\
\hline Goiter and adenomatous hyperplasia ${ }^{\mathrm{b}}$ & 91 & 1.6 & 1.0 & $(0-15)$ \\
\hline Thyroiditis $^{c}$ & 25 & 4.2 & 2.0 & $(0-20)$ \\
\hline Total & 504 & & & \\
\hline
\end{tabular}

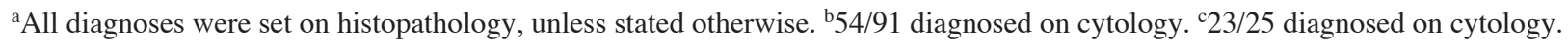

Table II. Patient and tumor characteristics and MIB-1 index for the 183 patients with PTC.

\begin{tabular}{lc} 
Patient data & \\
M/F gender & $40 / 143$ \\
Median age at surgery (range) & 53.5 years $(11-97)$ \\
Median MIB-1 index (range) & $2.0 \%(0-40)$ \\
Tumor characteristics at surgery & \\
Median tumor size (range) & $3 \mathrm{~cm}(0.3-12)$ \\
Patients with lymph node metastases & $79 / 183(43.2 \%)$ \\
Patients with distant metastases & $11 / 183(6 \%)$ \\
Patients with extrathyroidal growth & $57 / 183(31.1 \%)$ \\
Follow-up information & \\
Median follow-up time (range) & 6.2 years $(0.1-16.7)$ \\
Local recurrence & $13 / 183(7.1 \%)$ \\
Distant metastases & $16 / 183(8.7 \%)$ \\
Outcome at the end of follow-up & \\
Alive without disease & $145 / 183(79.2 \%)$ \\
Alive with disease & $7 / 183(3.8 \%)$ \\
Dead without disease & $14 / 183(7.7 \%)$ \\
Dead with disease (other cause) & $2 / 183(1.1 \%)$ \\
Dead of disease & $15 / 183(8.2 \%)$ \\
\hline
\end{tabular}

used to assess possible predictor factors. This showed that high MIB-1 index is indeed a significant predictor of increased risk of distant metastasis $(\mathrm{p}=0.000653)$, disease-related mortality $(\mathrm{p}=0.006)$ and local recurrence $(\mathrm{p}=0.000529)$. Moreover, age at operation turned out to be of statistical significance in relation to disease-related mortality $(\mathrm{p}=0.00017)$ and distant metastasis $(\mathrm{p}=0.0004)$. On the other hand, tumor size was not significantly associated to any of the end-points.

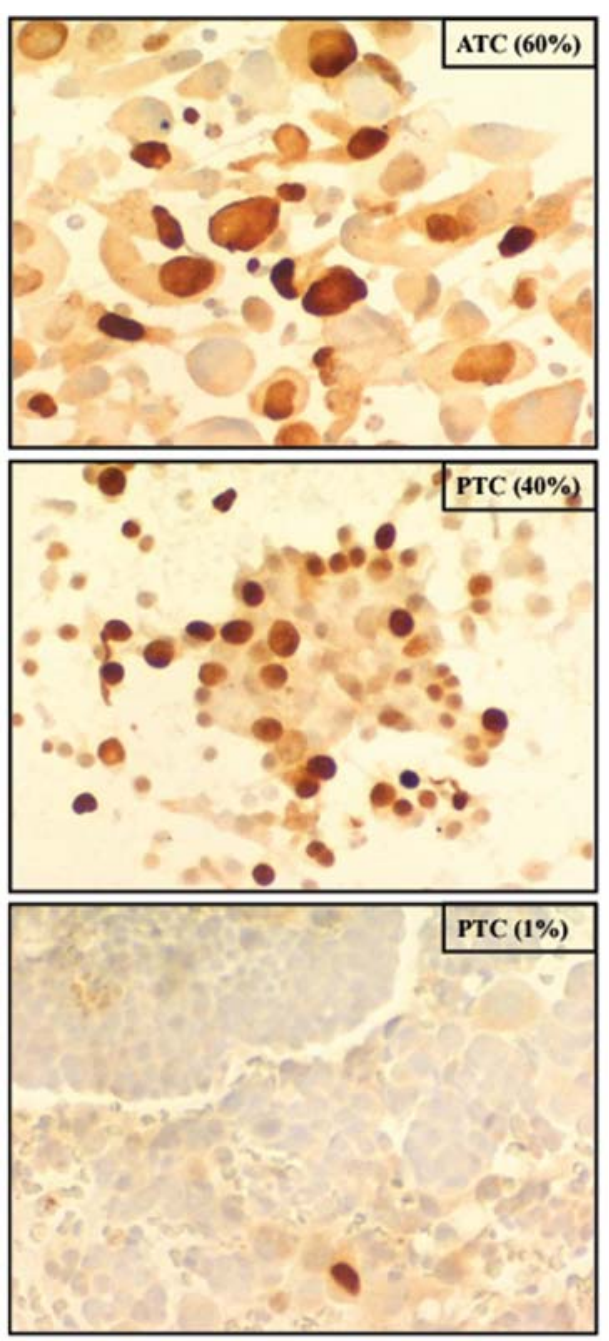

Figure 1. Photomicrographs, in high magnification, showing Ki-67/MIB-1 staining of fine needle aspiration biopsies from one case of ATC and two cases of PTC. The proportion of positively stained cells (brown color) is given in percentage. 


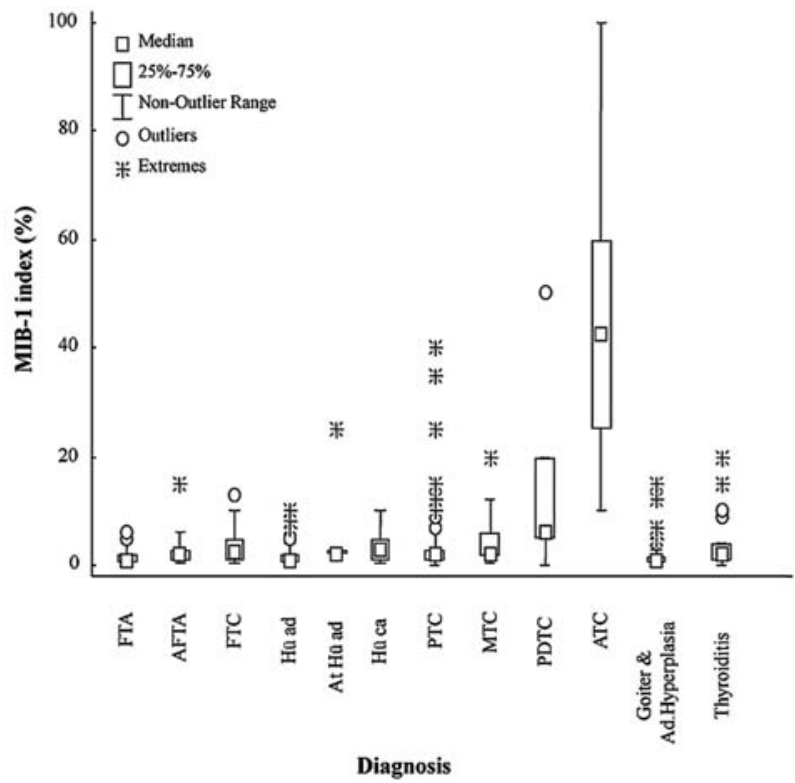

Figure 2. Box-plot illustrating the distribution of MIB-1 proliferation index values among different thyroid tumor groups and non-neoplastic lesions. MIB-1 is significantly higher in ATC in comparison with the rest of the tumors $(\mathrm{p} \leq 0.01)$ except PDTC and atypical Hürthle adenoma. (All abbreviations are according to Table I).
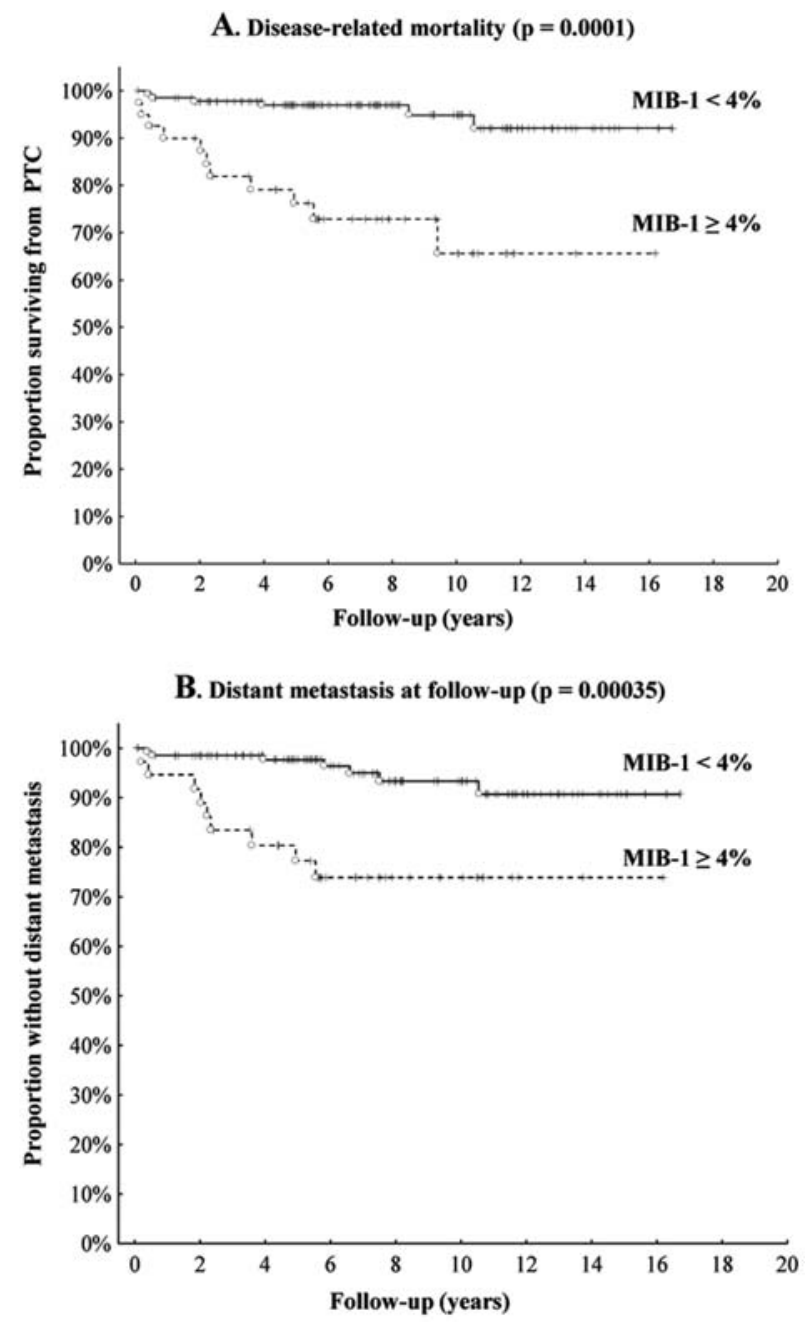

Figure 3. Kaplan-Meier curves illustrating the association between a high MIB-1 index ( $\geq 4 \%)$ and (A) disease-related mortality and (B) development of distant metastasis in patients with PTC.
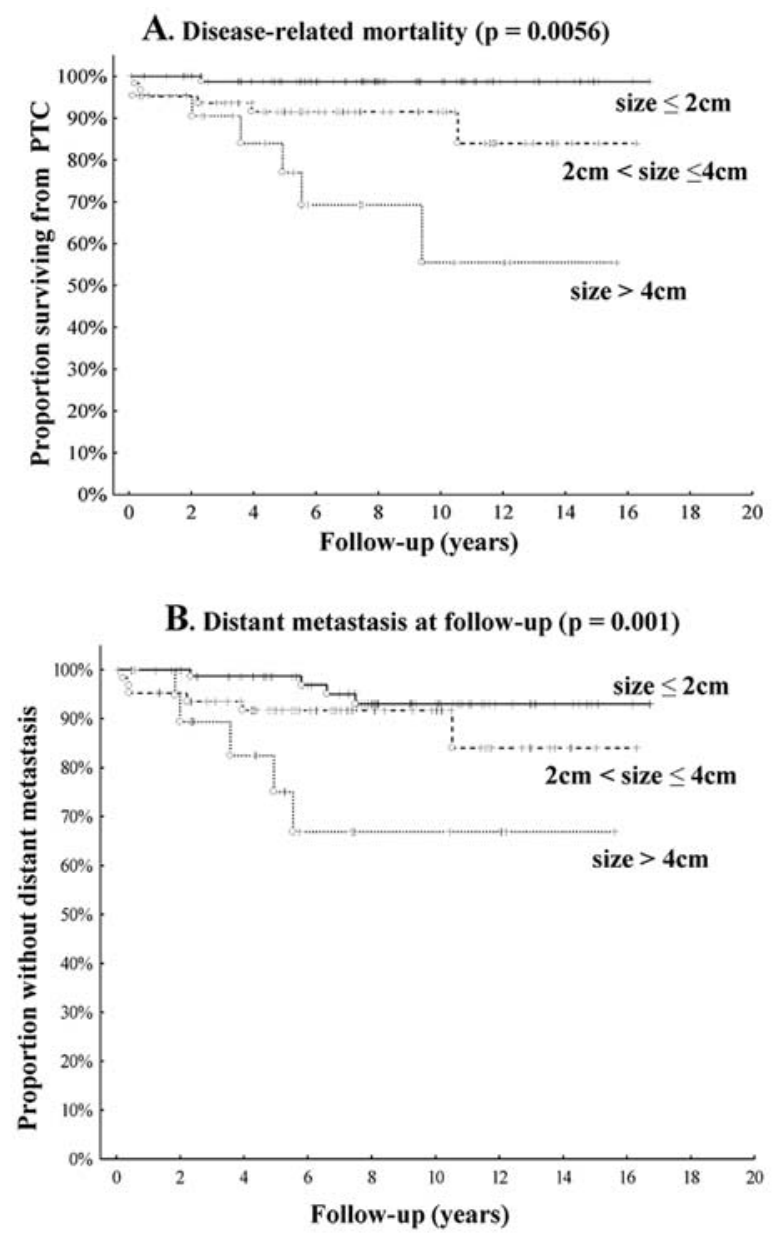

C. Local recurrence at follow-up $(p=0.00003)$

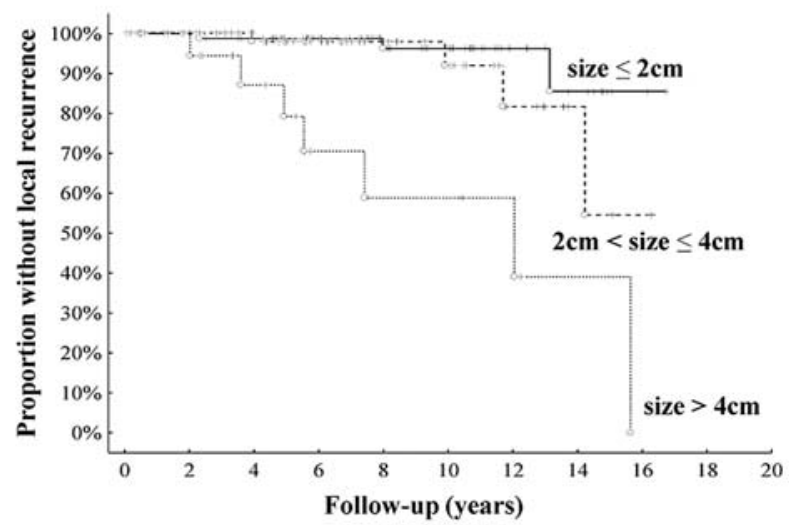

Figure 4. Kaplan-Meier curves illustrating the association between tumor size and (A) disease-related mortality, (B) development of distant metastasis and (C) development of local recurrence in patients with PTC.

\section{Discussion}

In 1984 Gerdes et al reported the production of a mouse monoclonal antibody, Ki-67, which could react with a human nuclear antigen present in all proliferating cells, but absent in resting cells (18). Their first findings were suggestive of a potent tool for determining the proportion of proliferating cells in a tumor. Since then, analysis of Ki-67 has been increasingly applied to assess proliferation index in cytological characterization of a wide range of tumors. A prognostic value has 
been established in, for example, breast cancer, soft tissue tumors and lymphomas (8).

In the field of thyroid oncology, the possible clinical utility of MIB-1 index has been an issue of controversy and a consensus has not been reached. Furthermore, with very few exceptions (19), studies of MIB-1 index in thyroid tumors have been carried out on histopathological material. However, the eventual goal should be to apply diagnostic and prognostic markers already in FNAB, thereby allowing adjustment of surgical strategy or addition of preoperative treatment. Working on routinely acquired cytology material is different from histopathology, in terms of both representativity and quantity of the specimen under investigation. This study is, to our knowledge, the first one dealing with preoperative assessment of MIB-1 index in such a large and broad-range thyroid material.

Our results were in concordance with published findings from immunohistochemical studies on surgical thyroid material. ATC and PDTC were strikingly distinct showing the highest MIB-1 labeling index. Interestingly, a significant progressive increase in MIB-1 along the spectrum of thyroid cancer progression has been described (20). In the case of well differentiated tumors, lower, but overlapping, values between groups were noted in our study. No significant difference in MIB-1 index between follicular tumors (FTA, atypical FTA, FTC) was observed, in agreement with some studies from immunohistochemical studies $(9,21)$. Nevertheless, significant differences in MIB-1 index between benign and malignant follicular tumors have been presented by others $(19,22,23)$. It should, however, be stressed that overlapping value ranges between follicular lesions suggest that MIB-1 index cannot be readily used to aid the morphological distinction between them (21). Although based on a limited number of cases, a similar overlap in MIB-1 index was noted between Hürthle cell adenomas and carcinomas in our material.

ATC showed significantly higher MIB-1 values compared with other tumor groups. Usually, FNAB cytology is a sensitive method in the diagnostics of ATC and immunocytochemistry adds rather little in establishing this diagnosis.

For PTC the diagnosis can be readily established by cytology and in our institution a $98 \%$ agreement between cytology and histopathology has been demonstrated (24). In the attempt to achieve a more accurate prognosis for PTC patients, many different scoring systems have been suggested that are generally based on tumor characteristics determined post-operatively. Based on our findings, a high preoperative MIB-1 index should be considered as a sign of increased aggressiveness and metastatic potential and, should our findings be verified in other series, an optimization of the therapeutic strategy could be discussed.

The extent of surgical treatment preferred, concerning lobectomy vs. total thyroidectomy as well as extent of nodal dissection, varies between different medical centres. Bilimoria et al showed that for patients with PTC $<1 \mathrm{~cm}$ in size, there was no significant difference in recurrence or survival when comparing total thyroidectomy to lobectomy (25). Despite its limitations, their study provides solid ground to support a less-than-total thyroidectomy for PTC which meet the following criteria: a) Absence of invasion of the thyroid capsule, b) Unifocal primary tumor of sporadic origin measuring $<1 \mathrm{~cm}$ in largest diameter, c) No lymph node or distant metastases and d) No unusual histopathological variants as laid out in the latest classification by WHO (3). Moreover, there are recent studies suggesting that central lymph node dissection - an intervention with an incremental risk of transient, or occassionaly permanent, hypoparathyroidism and recurrent laryngeal nerve palsy - should be carefully considered and reserved for papillary cancers $>1$ (26) or $2 \mathrm{~cm}$ (27). In all cases the benefit from a more aggressive surgical intervention should be balanced by the risk of complications, like the ones mentioned above, that might have a great effect in terms of the patients' quality of life.

As far as the prognostic value of MIB-1 proliferation index is concerned, this study strongly supports that a high MIB-1 index $(\geq 4 \%)$ on FNAB is associated with a significantly increased risk of distant metastasis and disease-related mortality. Moreover, small papillary carcinomas $(<10 \mathrm{~mm})$ with preoperatively detectable lymph node metastasis have a higher MIB-1 index in comparison with those that have either no or undetectable metastases only (28). By contrast, Siironen et al found no significant difference in MIB-1 index in relation to aggressive PTC, but in this case a lower MIB-1 cut-off value was selected (1\%) which might explain the result (29).

In summary, our study suggests that preoperative MIB-1 index may have a value in improving PTC prognostication and could develop into a marker useful in guiding choice of therapy.

\section{Acknowledgements}

The authors wish to thank Elisabeth Berg (Karolinska Institutet, Department of Learning, Informatics, Management and Ethics) for the expertise in statistical evaluation, as well as Torsten Hägerström and Lisa Ånfalk for valuable technical assistance. This study was financially supported by the Swedish Cancer Society, the Swedish Research Council, the Cancer Society in Stockholm, the Stockholm County Council and the Göran Gustafsson Foundation for Research in Natural Sciences and Medicine.

\section{References}

1. Dean DS and Gharib H: Epidemiology of thyroid nodules. Best Pract Res Clin Endocrinol Metab 22: 901-911, 2008.

2. Sherman SI: Thyroid carcinoma. Lancet 361: 501-511, 2003.

3. LiVolsi VA, Mazzaferri EL, Schneider AB, et al: Papillary Carcinoma. In: Classification of tumours: Pathology and genetics of tumours of endocrine organs. WHO classification of tumors. DeLellis RA, Heitz PU and Eng C (eds). IARC Press, Lyon, pp57-66, 2004.

4. Gharib H and Goellner JR: Fine-needle aspiration biopsy of the thyroid: an appraisal. Ann Intern Med 118: 282-289, 1993.

5. Saggiorato E, De Pompa R, Volante M, Cappia S, Arecco F, Dei Tos AP, Orlandi F and Papotti M: Characterization of thyroid 'follicular neoplasms' in fine-needle aspiration cytological specimens using a panel of immunohistochemical markers: a proposal for clinical application. Endocr Relat Cancer 12: 305-317, 2005.

6. Kjellman P, Wallin G, Hoog A, Auer G, Larsson C and Zedenius J: MIB-1 index in thyroid tumors: a predictor of the clinical course in papillary thyroid carcinoma. Thyroid 13: 371-380, 2003.

7. Cattoretti G, Becker MH, Key G, Duchrow M, Schluter C, Galle J and Gerdes $\mathrm{J}$ : Monoclonal antibodies against recombinant parts of the Ki-67 antigen (MIB 1 and MIB 3) detect proliferating cells in microwave-processed formalin-fixed paraffin sections. J Pathol 168: 357-363, 1992. 
8. Brown DC and Gatter KC: Ki67 protein: the immaculate deception? Histopathology 40: 2-11, 2002.

9. Mar KC, Eimoto T, Nagaya S and Tateyama H: Cell proliferation marker MCM2, but not Ki67, is helpful for distinguishing between minimally invasive follicular carcinoma and follicular adenoma of the thyroid. Histopathology 48: 801-807, 2006.

10. Mehrotra P, Gonzalez MA, Johnson SJ, Coleman N, Wilson JA, Davies BR and Lennard TW: Mcm-2 and Ki-67 have limited potential in preoperative diagnosis of thyroid malignancy. Laryngoscope 116: 1434-1438, 2006.

11. Kjellman P, Zedenius J, Lundell G, Backdahl M, Farnebo LO, Hamberger B, Larsson C and Wallin G: Predictors of outcome in patients with papillary thyroid carcinoma. Eur J Surg Oncol 32: 345-352, 2006.

12. Zajicek J: Aspiration biopsy cytology. Lymphology 10: 94-101, 1977.

13. Billgren AM, Tani E, Liedberg A, Skoog L and Rutqvist LE: Prognostic significance of tumor cell proliferation analyzed in fine needle aspirates from primary breast cancer. Breast Cancer Res Treat 71: 161-170, 2002.

14. Veronese SM, Maisano C and Scibilia J: Comparative prognostic value of Ki-67 and MIB-1 proliferation indices in breast cancer. Anticancer Res 15: 2717-2722, 1995.

15. Baloch Z, Carayon P, Conte-Devolx B, Demers LM, FeldtRasmussen U, Henry JF, LiVolsi VA, Niccoli-Sire P, John R, Ruf J, Smyth PP, Spencer CA and Stockigt JR: Laboratory medicine practice guidelines. Laboratory support for the diagnosis and monitoring of thyroid disease. Thyroid 13: 3-126, 2003.

16. British Thyroid Association: Royal College of Physicians: Report of the Thyroid Cancer Guidelines Update Group. In: Guidelines for the management of thyroid cancer. Perros P (ed). 2nd edition, Royal College of Physicians, London, 2007.

17. American Joint Committee on Cancer: Cancer Staging Manual. 6th edition, Springer, Chicago, 2002.

18. Gerdes J, Lemke H, Baisch H, Wacker HH, Schwab U and Stein H: Cell cycle analysis of a cell proliferation-associated human nuclear antigen defined by the monoclonal antibody Ki-67. J Immunol 133: 1710-1715, 1984.

19. Mehrotra A, Goel MM and Singh K: Ki-67 and AgNOR proliferative markers as diagnostic adjuncts to fine needle aspiration cytology of thyroid follicular lesions. Analytical and quantitative cytology and histology/the International Academy of Cytology (and) American Society of Cytology 24: 205-211, 2002 .
20. Saltman B, Singh B, Hedvat CV, Wreesmann VB and Ghossein R: Patterns of expression of cell cycle/apoptosis genes along the spectrum of thyroid carcinoma progression. Surgery 140: 899-905; discussion 905-896, 2006.

21. Rickert D, Mittermayer C, Lindenfelser R and Biesterfeld S: MIB-1 immunohistometry of follicular adenoma and follicular carcinoma of the thyroid gland. Analytical and quantitative cytology and histology/the International Academy of Cytology (and) American Society of Cytology 22: 229-234, 2000.

22. Erickson LA, Jin L, Wollan PC, Thompson GB, van Heerden J and Lloyd RV: Expression of p27kip1 and Ki-67 in benign and malignant thyroid tumors. Mod Pathol 11: 169-174, 1998.

23. Nakamura N, Erickson LA, Jin L, Kajita S, Zhang H, Qian X, Rumilla K and Lloyd RV: Immunohistochemical separation of follicular variant of papillary thyroid carcinoma from follicular adenoma. Endocr Pathol 17: 213-223, 2006.

24. Werga P, Wallin G, Skoog L and Hamberger B: Expanding role of fine-needle aspiration cytology in thyroid diagnosis and management. World J Surg 24: 907-912, 2000.

25. Bilimoria KY, Bentrem DJ, Ko CY, Stewart AK, Winchester DP, Talamonti MS and Sturgeon C: Extent of surgery affects survival for papillary thyroid cancer. Ann Surg 246: 375-381, 2007.

26. Dralle $\mathrm{H}$ and Machens A: Surgical approaches in thyroid cancer and lymph-node metastases. Best Pract Res Clin Endocrinol Metab 22: 971-987, 2008.

27. Lee YS, Kim SW, Kim SW, Kim SK, Kang HS, Lee ES and Chung KW: Extent of routine central lymph node dissection with small papillary thyroid carcinoma. World J Surg 31: 1954-1959, 2007.

28. Ito Y, Uruno T, Takamura Y, Miya A, Kobayashi K, Matsuzuka F, Kuma K and Miyauchi A: Papillary microcarcinomas of the thyroid with preoperatively detectable lymph node metastasis show significantly higher aggressive characteristics on immunohistochemical examination. Oncology 68: 87-96, 2005.

29. Siironen P, Louhimo J, Nordling S, Ristimaki A, Maenpaa H, Haapiainen R and Haglund C: Prognostic factors in papillary thyroid cancer: an evaluation of 601 consecutive patients. Tumour Biol 26: 57-64, 2005 